\title{
THE FORMATION OF ALDEHYDES AND KETONES OZONATION BY-PRODUCTS AND THEIR VARIATION THROUGH GENERAL WATER TREATMENT PLANT IN HAMADAN, IRAN
}

\author{
SAMADI M.T. ${ }^{1}$ \\ AZARIAN G. ${ }^{1}$ \\ SEIFIPOUR F. ${ }^{1}$ \\ HUANG C-P. ${ }^{2}$ \\ YANG $X .^{3}$ \\ ALI POORMOHAMMADI ${ }^{4, *}$
}

\author{
${ }^{1}$ Department of Environmental Health Engineering \\ Faculty of Health and Research Center for Health sciences \\ Hamadan University of Medical Sciences, Hamadan, Iran \\ ${ }^{2}$ Department of Civil and Environmental Engineering \\ University of Delaware, USA \\ ${ }^{3}$ School of Environmental Science \& Engineering \\ Sun Yat-sen University, Guangzhou, China, 510275 \\ ${ }^{4}$ Social Development \& Health Promotion Research Center \\ Kermanshah University of Medical Sciences, Kermanshah, Iran
}

Received: $16 / 03 / 2015$

Accepted: 30/09/2015

*to whom all correspondence should be addressed: e-mail: apoormohammadi000@yahoo.com

\section{ABSTRACT}

The effect of pre-ozonation on the formation of four aldehydes (i.e. formaldehyde, acetaldehyde, glyoxal, methyl glyoxal) and two ketones (i.e. pyruvic acid and glioxalic acid) at the Beheshti water treatment plant in Hamadan, Iran were studied. Water samples were taken from the treatment plant at different points of the treatment train during September-January, 2013. The variation of formaldehyde, acetaldehyde, glyoxal, methyl glyoxal, pyruvic acid, and acid glioxalic concentration within treatment process were monitored in September and January. The results indicated that formaldehyde and acetaldehyde were the most abundant aldehyde species in the raw water. After pre-ozonation all of the aldehydes and ketones reached the maximum concentration. On the contrary, results show that the coagulationfiltration process was beneficial to the removal of aldehydes and ketones. Also, the results indicated that the level of aldehydes was increased after post chlorination. The percent increase was 52.3, 34.6, 12.1, 26.8 and $38 \%$ for formaldehyde, acetaldehyde, glyoxal, methyl glyoxal and glyoxalic acid, respectively, in September. Therefore, final chlorination led to increase in the formation of aldehydes in the pre-ozonated water. Ketones were not detected in the post-chlorinated water. Moreover, there was no correlation between total organic carbon (TOC) and total aldehyde and total ketone in water samples.

Keywords: Aldehydes, Ketones, Ozonation, By-product

\section{Introduction}

Disinfection is a widely used process at water purification plants to ensure safe drinking water. Disinfection can be carried out by a variety of techniques with chemical method being the most commonly used. Common disinfectants include chlorine, chlorine dioxide and ozone (Jung et al., 2007). Among these disinfectants, ozonation has received increasing attention in drinking water disinfection practice (Chou et al., 2009; Reungoat et al., 2010). Ozone is a strong oxidant and microbicide (Derrouiche et al., 2013; Asgari et al., 2013), which can eliminate or decompose many undesirable color, taste, odor, forming compounds, toxic substances and micro-pollutants from water. Since ozone treatment produces a lower level of 
halogenated disinfection by-products, it has been widely accepted as an alternative technology to chlorination in water treatment (Kiss et al., 2013; Rivera-Utrilla and Sánchez-Polo, 2002). Moreover, ozone oxidation can be used to remove disinfection by-products and microorganisms in water (Kasprzyk-Horden et al., 2003; Chiang et al., 2009). On the other hand, the reaction of ozone with natural organic matter (NOM) in water could lead to the formation of undesirable by-products, e.g., brominated by-products among others, which are major concerns for source waters containing bromide. Other ozonation byproducts such as short chain aldehydes (e.g., formaldehyde, acetaldehyde, glyoxal and methyl glyoxal), carboxylic acids (e.g., oxalic acid, formic acid, acetic acid and soxilic acid) and ketones (e.g., pyruvic acid, glioxalic acid and ktomalonic acid) have been identified (Faria et al., 2006; Oliviero et al., 2003). These above chemicals are oxygenated organic compounds with low molecular weight, formed from the oxidative breakdown of NOM during ozone treatment (Dabrowska et al., 2003; Nawrochi et al., 2003). The formation of these by-products depends on variables such as ozone dose, temperature, $\mathrm{pH}$ and organic matter present in the water (Sung et al., 2012). These ozonation by-products are relatively volatile, polar, and reactive and have potential adverse health problems. For example, aldehydes can cause upper respiratory tract irritation, respiratory tumors (especially after inhalation exposure with formaldehydes) and allergic contact dermatitis in human. In addition, the presence of these compounds in drinking water can cause undesirable flavor in water supply (Müller et al., 2012). Meanwhile, these compounds are easily biodegradable and can become substrates for microbial re-growth in the water distribution network. All of these by-products are formed through the reaction of ozone with NOM in water (Hammes et al., 2006). The occurrence of aldehydes has been widely reported in many water treatment plants where pre-ozonation is used (Dabrowsk et al., 2003). Most of these by-products reported previously were from laboratory studies (Jung et al., 2007; Karnik et al., 2005). There are few studies about the formation of disinfection by-products from drinking water by ozonation, especially in full-scale operation. Insomuch as, these compounds are directly related to public health, it became evident that there is need to study the formation of by-products from the reaction between ozone and NOM. The Shahid Beheshti Water Treatment Plant in Hamadan, Iran, has provided water supply demand to about 50 percent of the population in the municipal Hamadan. The treatment capacity of this plant is about $1000 \mathrm{I} \mathrm{s}^{-1}$. Hamadan is among the oldest Iranian cities and one of the oldest in the world with a population of 473,149 according to 2006 census. Therefore, we have selected the plant as a study site. The objective was to assess the formation of ozone disinfection by-products, namely, aldehydes and ketones, at the treatment plant as affected by general water treatment processes such as coagulationfiltration and post chlorination. Moreover, the relationship between TOC concentration and total aldehyde and total ketone in samples was assessed.

\section{Methods}

\subsection{Water source}

Water samples were taken from the Shahid Beheshti Treatment Plant, which is the major provider of public water supply of Hamadan province, Iran. The Hamadan Shahid Beheshti Treatment Plant is fed from two Ecbatana and Abshineh dams at an average flow rate of 350 to $400 \mathrm{I} \mathrm{s}^{-1}$. Fig. 1 shows the water treatment train of the Shahid Beheshti Plant and water sampling points of the present study. Water samples were collected from the following points at the treatment plant: inlet raw water $\left(A_{1}\right)$, postozonation $\left(A_{2}\right)$, post-coagulation-filtration $\left(A_{3}\right)$, and outlet $\left(A_{4}\right)$. With considering $\alpha=0.05$ and the possibility of actual inflation about $0.95,100$ samples were taken. In order to detect aldehydes and ketones, the sampling was done in four parts: inlet raw water $\left(A_{1}\right)$, pre-ozonation $\left(A_{2}\right)$, coagulationfiltration $\left(A_{3}\right)$, and outlet $\left(A_{4}\right)$ and one sample were taken from each part. For measuring TOC and physical and chemical parameters, two parts (inlet raw water $\left(A_{1}\right)$ and outlet $\left(A_{4}\right)$ were selected and one sample was taken from each part. Samples were collected in amber glass $40 \mathrm{ml}$ vials with PTFE-lined screw caps. Prior to sampling, $15 \mathrm{mg}$ of copper (II) sulfate pentahydrate was added to each vial to inhibit bacteriological decay of carbonyl compounds. Water samples were stored at $4{ }^{\circ} \mathrm{C}$ in the refrigerator until analysis. Four aldehydes (i.e. formaldehyde, acetaldehyde, glyoxal, methyl glyoxal) and two ketones (i.e. 
pyruvic acid and glioxalic acid) were the major ozonated disinfection by-products investigated in this study. All experiments were conducted two times and the errors were between 0.69 and 0.81 , being calculated with ICC (Intraclass Correlation Coefficient).

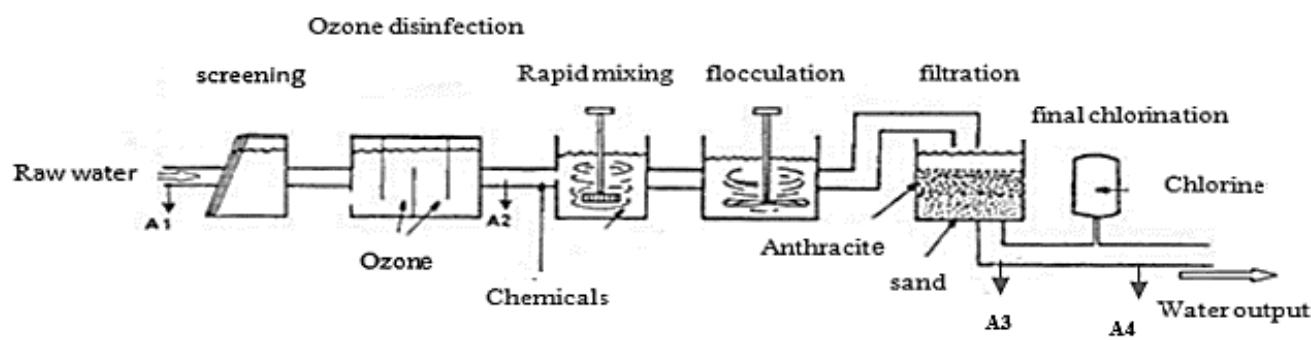

Figure 1. Schematic flow chart of the Shahid Beheshti Water Treatment Plant and sampling points

$$
\left(A_{1}, A_{2}, A_{3} \text { and } A_{4}\right)
$$

Table 1 summarizes the general physical and chemical characteristics of the raw and finished waters. The kind of chlorination in this water treatment plant is gaseous chlorination (chlorination dosage $=2 \mathrm{mg} \mathrm{l}^{-1}$ and residual chlorine of treated water $=1-1.2 \mathrm{mg} \mathrm{l}^{-1}$ ).

Table 1. General physical and chemical characteristics of the raw and finished waters

\begin{tabular}{ccc}
\hline Parameter & Raw water & Treated water \\
\hline Total hardness $\left(\mathrm{mg} \mathrm{l}^{-1}\right.$ as $\left.\mathrm{CaCO}_{3}\right)$ & 117.2 & 115.2 \\
\hline Alkalinity $\left(\mathrm{mg} \mathrm{l}^{-1}\right.$ as CaCO & 119.4 \\
\hline Temperature $\left.{ }^{\circ} \mathrm{C}\right)$ & 115.2 & 24.9 \\
\hline TOC $\left(\mathrm{mg} \mathrm{l}^{-1}\right)$ & 15 & 2.67 \\
\hline Electrical conductivity $\left(\mu \mathrm{cm}^{-1}\right)$ & 3.27 & 243 \\
\hline $\mathrm{TDS}\left(\mathrm{mg} \mathrm{l}^{-1}\right)$ & 230 & 155.5 \\
\hline $\mathrm{pH}$ & 147.2 & 7.3 \\
\hline Turbidity $(\mathrm{NTU})$ & 7.6 & 0.38 \\
\hline Phosphate $\left(\mathrm{mg} \mathrm{l}^{-1}\right)$ & 14 & 0.043 \\
\hline Nitrate $\left(\mathrm{mg} \mathrm{l}^{-1}\right)$ & 0.032 & 3.4 \\
\hline Nitrite $\left(\mathrm{mg} \mathrm{l}^{-1}\right)$ & 2.7 & 0.001 \\
\hline
\end{tabular}

\subsection{Reagents and Standards}

The derivative reagents of $0-2,3,4,5,6$-pentafluorobenzyl-hydroxylamine hydrochloride (98\%) were purchased from Aldrich (USA). Other chemicals, 1,2-diboromopropan (used as an internal standard), potassium hydrogen phethalate and $n$-hexane (for analyte extraction), reagents acetonitrile (99\%), methanol, sulfuric acid (98\%), copper sulphate penta hydrate, ammonium chloride and ammonium sulfate were purchased from Merck (Germany). Aldehyde standard solutions (formaldehyde 37\%, acetaldehyde $99 \%$, methyl glyoxal $40 \%$ and glyoxal $40 \%$ ) were prepared from stock solution.

\subsection{Instrumentation}

The measurement of carbonyl compounds: aldehydes and ketones was done based on the method described in EPA Method 556 (EPA, 1998), which is an optimized chromatographic way for detecting carbonyl compounds in drinking water in influent or effluent of water works. In this method, the analytes are derived in relevant oxime of pentafluorobenzyl. Then, the oximes are extracted from the water via hexane. The extracted analytes are detected through gas chromatography (ECD/GC, SHIMADZU 2010, made in Japan) and the amount of their concentrations is calculated by a standard calibration. In order to adjust $\mathrm{pH}$ (at 4) potassium hydrogen phthalate was used, so $2^{\prime}, 4^{\prime}, 5^{\prime}$-trifluoroacetophenone was applied as an alternative standard. The carbonyl compounds were derivatized using PFBOA (at $35^{\circ} \mathrm{C}$ for $2 \mathrm{~h}$ ). 
Sulfuric acid was added to complete the derivatization reaction. Moreover, 1,2-dibromopropane was added as internal standard and oxime derivatives were purified using sulfuric acid $(0.2 \mathrm{~N})$, and finally $\mathrm{n}$ hexane was used for extraction. Gas chromatography device equipped with an electron capture detector (ECD), capillary column CP-SIL 8CB $30 \mathrm{~m}$ in length, $250 \mu \mathrm{m}$ in internal diameter and thick lining of $0.25 \mu \mathrm{m}$ in a split of $1: 5$. The column temperature program was $50^{\circ} \mathrm{C}$ initially and increased at $5^{\circ} \mathrm{C} \mathrm{min}^{-1}$ to $280^{\circ} \mathrm{C}$ ( 5 min of retention time). The inlet temperature (injector) was set at $280^{\circ} \mathrm{C}$ and the ECD temperature was $300{ }^{\circ} \mathrm{C}$. The helium gas at $11 \mathrm{psi}$ and $35 \mathrm{ml} \mathrm{min}^{-1}$ was the carrier gas and nitrogen gas was the auxiliary gas (for makeup). In this study the detection limit for aldehydes (i.e. formaldehyde, acetaldehyde, glyoxal, methyl glyoxal) and two ketones (i.e. pyruvic acid and glioxalic acid) was in the $\mathrm{ppb}\left(\mu \mathrm{g}^{-1}\right)$ range using the ECD/GC technique. To determine TOC, Standard Method C5310 was followed (APHA 1998). TOC were analyzed using a Shimadzu TOC-5000A analyzer.

\subsection{Statistical analysis}

The data were analyzed using Mann-Whitney $U$ test in SPSS. The significant differences were observed between two methods $(p<0.05)$. Also in both groups of samples the assumption of normality was verified with Kolmogorov-Smirnov test. According to the statistical analysis, there was no significant correlation between TOC and total aldehyde ( $P$-value $=0.667)$ and Ketones $(0.333)$ in water samples.

\section{Results and discussion}

In this present study, four aldehydes including formaldehyde, acetaldehyde, glyoxal, methyl glyoxal and two ketones including pyruvic acid and glioxalic acid were studied during water treatment at Shahid Beheshti Water Treatment Plant. Fig. 2 shows the GC/ECD Chromatogram for (a) raw water, (b) after preozonation, (c) after coagulation -filtration and (d) after final chlorination.

Table 2(a) shows the concentration of formaldehyde, acetaldehyde, glyoxal, and methyl glyoxal in September. Results show that the formaldehyde and acetaldehyde concentration were $5.2 \mathrm{\mu g}^{-1}$ and 4.8 $\mu \mathrm{g} \mathrm{I}^{-1}$, respectively, in the raw water, while no glyoxal and methyl glyoxal were detected. Results were similar to those of Dabrowska et al., (2005) and Ivancev-Tumbas et al., (2001). It is interesting that aldehydes were present in raw waters before disinfection. As shown in the table 2(a), after pre-ozonation (at ozone dose in the range 2 to $3 \mathrm{mg} \mathrm{l}^{-1}$ ), the concentration of all four aldehydes were increased with formaldehyde being present at the highest level of $20 \mathrm{\mu g}^{-1}$. The acetaldehyde was increased from 4.8 to $15.5 \mathrm{\mu g}^{-1}$. Glyoxal and methyl glyoxal were formed rapidly after ozonation and rose to 10.2 and 13.2 $\mu \mathrm{g} \mathrm{I}^{-1}$, respectively. In general, after pre-ozonation the total aldehyde concentration was increased from 10 to $58.9 \mathrm{~g} \mathrm{I}^{-1}$. The increase in aldehydes can be attributed to the conversion of high-molecular-weight compounds to those of lower molecular weight by ozone oxidation. Many have reported the increase in aldehydes during the ozonation of natural waters (Dabrowska et al., 2003; Ivancev-Tumbas et al., 2001). The increase in aldehydes depends on the ozone dose and organic matter in natural waters. Due to the presence of organic compounds in Ecbatana and Abshineh dams, it was expected that the water would have high disinfection by-product formation potential during ozonation. Therefore, the reaction of ozone with NOM in the raw water during pre-ozonation could lead to the formation glyoxal and methyl glyoxal, and increase the formaldehyde and acetaldehyde level. Table 2(b) shows the concentration of aldehydes in January. As shown in Table 2(b), only formaldehyde was observed at concentration of $3.2 \mathrm{\mu g} \mathrm{l}^{-1}$, while other acetaldehydes, glyoxal, and methyl glyoxal were not detected. After pre-ozonation the concentration of all four aldehydes were increased, but the concentration was a few ppm less than that in September. Although there have been contradictory reports in the literature that how temperature affects the formation of ozone by-products, we can claim that the decrease in ozonation by-products in January versus September could be attributed mainly to temperature difference. The average water temperature of Shahid Beheshti Water treatment plant in September and January were 24.9 and $15.0^{\circ} \mathrm{C}$, respectively. Our results were in agreement with those reported by Dabrowska et al., who studied the distribution of aldehydes in Polish lakes and reported an increase in concentration of some aldehydes 
with increase in air temperature in the Polish lake waters (Dabrowska et al., 2014). Moreover, it has been reported that temperature can have both positive and negative effect on DBP formation.

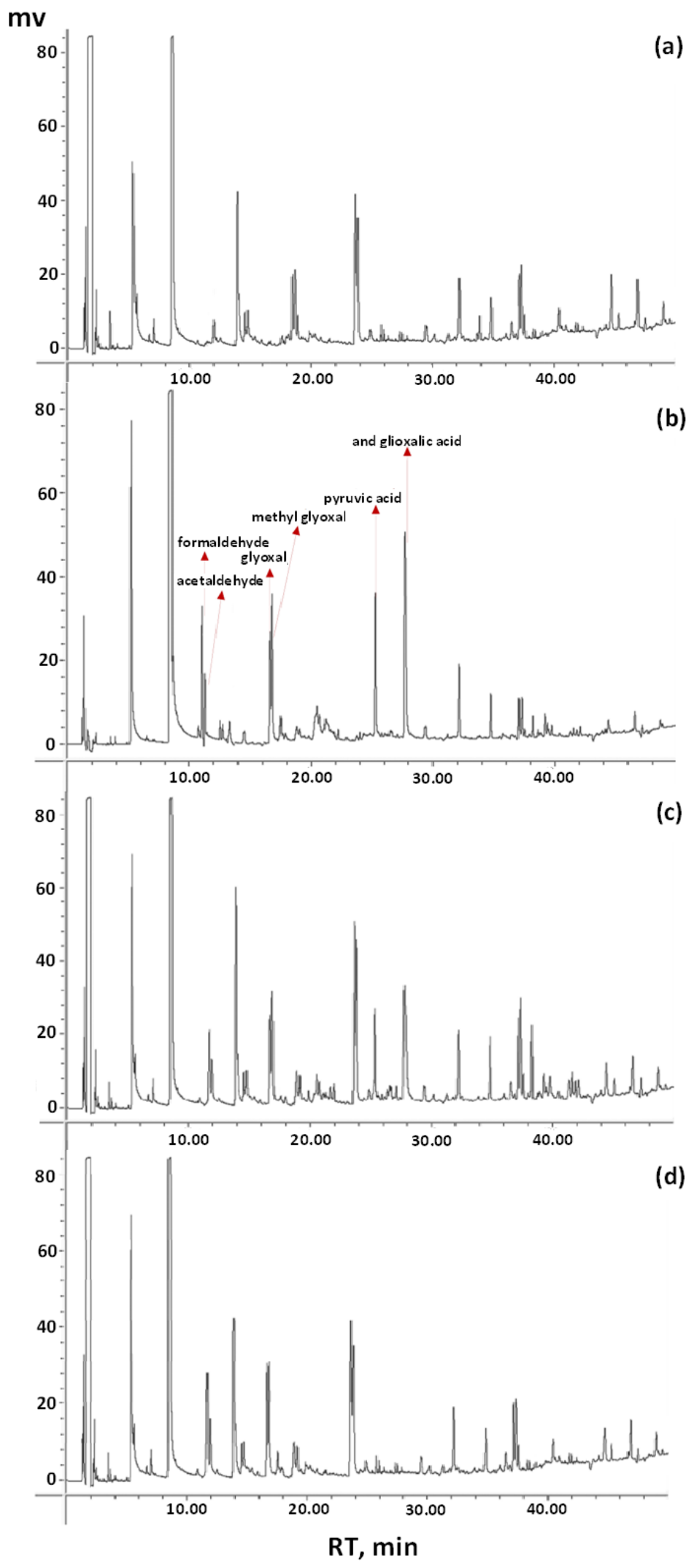

Fig. 2. GC/ECD Chromatogram for (a) raw water, (b) after pre-ozonation, (c) after coagulation -filtration and (d) after final chlorination. 
The formation of THMs, HAAs and bromate ion has been shown to increase with temperature (Dabrowska et al., 2014; Siddiqui et al., 1996); whereas the concentration of haloketone and chloropicrin formation is decreased with temperature. There are two simple explanations for contradictory reports about the effect of temperature on ozonation by-products: the content of these pollutants can decrease with temperature increase, the amount of volatility of ozonation by-products and the intensity of biological destruction of the pollutants. On the other hand, when temperature rises, the concentration of these pollutants will increase because of an increase in the activity and growth of some algae like phytoplankton.

Table 2. The concentration of aldehydes in the water treatment plant, a: September and b: January

\begin{tabular}{ccccccc}
\hline Parameter & Raw water & $\begin{array}{c}\text { pre-ozonation } \\
\text { water }\left(\mathbf{O}_{\mathbf{3}}=\mathbf{2} \mathbf{~ m g ~ I}^{-1}\right)\end{array}$ & \multicolumn{2}{c}{ filtration water } & \multicolumn{2}{c}{ chlorination water } \\
\hline & $\begin{array}{c}\text { Concentration } \\
\left(\mu \mathrm{g} \mathrm{I}^{-1}\right)\end{array}$ & $\begin{array}{c}\text { Concentration } \\
\left(\mu \mathrm{g} \mathrm{I}^{-1}\right)\end{array}$ & $\begin{array}{c}\text { Concentration } \\
\left(\mu \mathrm{g} \mathrm{I}^{-1}\right)\end{array}$ & $\begin{array}{c}\text { Percent } \\
\text { removal }\end{array}$ & $\begin{array}{c}\text { Concentration } \\
\left(\mu \mathrm{g} \mathrm{I}^{-1}\right)\end{array}$ & $\begin{array}{c}\text { Percent } \\
\text { increase }\end{array}$ \\
\hline Formaldehyde & 5.2 & 20 & 10.5 & 47.5 & 16 & 52.3 \\
\hline Acetaldehyde & 4.8 & 15.5 & 7.8 & 49.6 & 10.5 & 34.6 \\
\hline Glyoxal & $\mathrm{N}-\mathrm{D}^{*}$ & 10.2 & 8.2 & 19.6 & 9.5 & 15.8 \\
\hline Methyl glyoxal & $\mathrm{N}-\mathrm{D}$ & 13.2 & 6.7 & 49.2 & 8.5 & 26.8 \\
\hline b & 3.2 & 18 & 8.5 & 52.7 & 14.3 & 68.2 \\
\hline Acetaldehyde & $\mathrm{N}-\mathrm{D}$ & 10.5 & 5.8 & 44.7 & 7.5 & 29.3 \\
\hline Glyoxal & $\mathrm{N}-\mathrm{D}$ & 7.2 & 6 & 16.6 & $\mathrm{~N}-\mathrm{D}$ & - \\
\hline Methyl glyoxal & $\mathrm{N}-\mathrm{D}$ & 10.2 & 8.7 & 14.7 & $\mathrm{~N}-\mathrm{D}$ & - \\
\hline
\end{tabular}

${ }^{*}$ Not detected

Table 3 shows the concentration of ketones in the water treatment plant. Results indicate that there were no ketones detected in the raw water in September or January. In September, the concentration of pyruvic acid and glyoxalic acid, after pre-ozonation at ozone dose in the range 2 to $3 \mathrm{mg} \mathrm{l}^{-1}$, were raised to 13.5 and $11.8 \mathrm{\mu g} \mathrm{I}^{-1}$, respectively, versus 11.5 and $7.7 \mu \mathrm{g} \mathrm{I}^{-1}$, respectively, in January. Results clearly indicated that the concentration of ozonation by-products present in the water in January was slightly less than that in September. As mentioned above, the decrease in ozonation by-products in January versus September could be attributed mainly to temperature difference.

Table 3. The ketones concentration within water treatment plant, a: September and b: January

\begin{tabular}{|c|c|c|c|c|c|c|c|}
\hline & \multirow{2}{*}{ Parameter } & \multirow{2}{*}{$\begin{array}{c}\text { Raw water } \\
\text { Concentration } \\
\left(\mu \mathrm{g} \mathrm{I}^{-1}\right)\end{array}$} & \multirow{2}{*}{$\begin{array}{c}\text { pre-ozonation } \\
\text { water }\left(\mathrm{O}_{3}=\mathbf{2} \mathrm{mg} \mathrm{l}^{-1}\right) \\
\begin{array}{c}\text { Concentration } \\
\left(\mu \mathrm{g} \mathrm{I}^{-1}\right)\end{array}\end{array}$} & \multicolumn{2}{|c|}{ filtration water } & \multicolumn{2}{|c|}{ chlorination water } \\
\hline & & & & $\begin{array}{c}\text { Concentration } \\
\left(\mu \mathrm{gl}^{-1}\right)\end{array}$ & $\begin{array}{l}\text { Percent } \\
\text { removal }\end{array}$ & $\begin{array}{c}\text { Concentration } \\
\left(\mu \mathrm{g} \mathrm{I}^{-1}\right)\end{array}$ & $\begin{array}{l}\text { Percent } \\
\text { increase }\end{array}$ \\
\hline \multirow{2}{*}{$\mathbf{a}$} & Pyruvic acid & $\mathrm{N}-\mathrm{D}^{*}$ & 13.5 & 7.8 & 42.2 & $\mathrm{~N}-\mathrm{D}$ & - \\
\hline & Glyoxalic acid & $\mathrm{N}-\mathrm{D}$ & 11.8 & 6.5 & 44.9 & $N-D$ & - \\
\hline \multirow[t]{2}{*}{ b } & Pyruvic acid & $\mathrm{N}-\mathrm{D}$ & 11.5 & 7 & 31.9 & $N-D$ & - \\
\hline & Glyoxalic acid & $\mathrm{N}-\mathrm{D}$ & 7.7 & 5.7 & 25.9 & $N-D$ & - \\
\hline
\end{tabular}

${ }^{*}$ Not detected

As can be observed in Table 2(a) the aldehydes were removed slightly after coagulation-filtration unit. In September, the removal percent via coagulation-filtration processes were 47.5, 49.6, 19.6 and $49.2 \%$ for formaldehyde, acetaldehyde, glyoxal and methyl glyoxal, respectively. According to the results the coagulation-filtration process favored the removal of aldehydes, but not glyoxals. It is known that glyoxals are more difficult to remove than other aldehydes. Our findings were consistent with Weinberg et al., (1993) and Cervi et al., (1993). A similar trend was observed in January, although the concentrations of aldehydes in January were slightly less than that of aldehydes in September. Table 3(b) also reports the percent removal of ketones by the coagulation-filtration process. According to the results, the removal of pyruvic acid and glyoxalic acid by the coagulation-filtration unit were 42.2 and $44.9 \%$, respectively. Thus, the coagulation-filtration process is also effective in ketones removal. The removal may be contributed from filtration process where biological activities took place. 
Most water chlorination plants also use chlorine as a secondary disinfectant to maintain residual disinfection capacity in the distribution system. In Shahid Beheshti treatment plant chlorine was also added after the filtration unit. Table 2(a) shows the effect of final chlorination on the formation of aldehydes. Results indicated that the level of aldehydes increased after chlorination in September, at 52.3, 34.6, 12.1 and $26.8 \%$, for formaldehyde, acetaldehyde, glyoxal and methyl glyoxal, respectively. Therefore, final chlorination led to increase of formation of aldehydes in the pre-ozonated water. This may be attributed to the synergistic oxidation effects of simultaneously applying both disinfectants. Results of several studies of ozone oxidation followed by chlorination showed increased, rather than decreased, levels of THMs, possibly due to the formation of aldehydes by ozonation (Trussell \& Umphres 1978). Also, Yang demonstrated that in most water pre-ozonation increased the formation of chloral hydrate, trichloronitromethane and haloketones while decreased the level of haloacetonitriles during chlorination (Yang et al., 2012). In addition, another similar study showed the level of aldehydes increased after chlorination, which is in agreement with our results (Dabrowska et al., 2005). Similar pattern was observed in January for formaldehyde and acetaldehyde after chlorination, while no glyoxal and methyl glyoxal were detected. Therefore, it is significant to note that post-chlorination process could contribute to the formation of aldehydes pre-ozonation water treatment plant.

Based on the results (Table $3 \mathrm{~b}$ ), ketones were not detected in the post-chlorinated water. In this part of the water treatment plant, ketones may be oxidized to other compounds by post-chlorinated process. There are no other similar published studies which can be compared with this part of our findings.
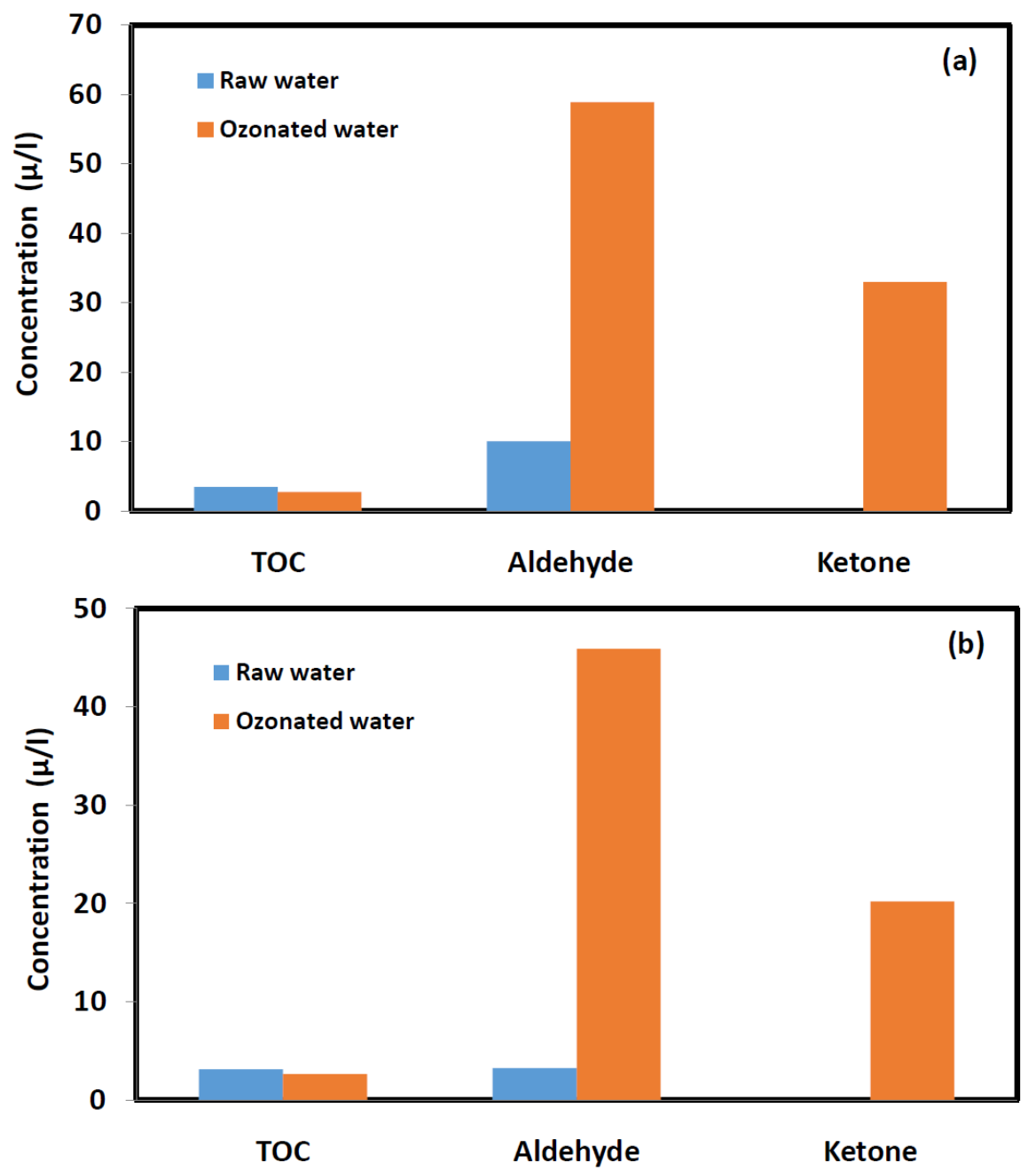

Figure 3. Determination of correlation between TOC concentration and aldehyde and ketone produced: (a) January (b) September. 
TOC is the primary surrogate for quantifying NOM in water supplies. It was reported above that an increase in TOC level in the water increased the formation of aldehyde during ozonation. In the present study, TOC concentration was monitored to determine the relationship between TOC and aldehydes in samples. Fig. 3 (a) gives the total aldehyde and TOC concentration. The results show that in raw water with a TOC of $3.27 \mathrm{mg} \mathrm{l}^{-1}$, which total aldehyde was $6.6 \mathrm{\mu g} \mathrm{l}^{-1}$. The increase in total aldehyde was positively related to the increase in initial TOC (Fig. 3 a). Additionally, after pre-ozonation TOC was slightly decreased while the total aldehyde sharply increased to $52.4 \mathrm{mg} \mathrm{I}^{-1}$. As discussed above, this increase in aldehydes can be attributed to the conversion of high-molecular-weight compounds to those of lower molecular weight by ozone oxidation (Dabrowska et al., 2003; Ivancev-Tumbas et al., 2001). However, there was no significant correlation between TOC and total aldehyde in water samples ( $P$-value $=0.14)$. The results were in agreement with that reported by Dabrowska et al., (2005) but disagreed with results by Schechter et al., (1995). Moreover, the correlation between TOC and ketones produced in water samples was also investigated. Fig. 3 (b) shows the total ketone and TOC. No ketones were detected in the raw water; but after pre-ozonation the formation of ketones increased sharply with the decrease in TOC. Again, there was no correlation between the formation of ketones and TOC in water samples ( $P$-value $=0.29$ ).

\section{Conclusions}

In this study the variation of formaldehyde, acetaldehyde, glyoxal, methyl glyoxal, pyruvic acid and acid glioxalic concentration within the treatment processes at full scale Shahid Beheshti water treatment plant were monitored. The results indicated:

- Aldehydes generally were present in the raw waters, even before the points of disinfection. Also, among the measured aldehydes, formaldehyde and acetaldehyde were the most abundant species in the raw water. On the contrary, ketones were not detected in the raw water.

- After pre-ozonation, all of the aldehydes and ketones reached the maximum concentration.

- The formation of aldehydes increased with the increase of temperature. Ozonation by-products formed in January were lower than those in September.

- The coagulation-filtration process was beneficial to the removal of aldehydes and ketones, however the removal efficiency for glyoxals was low.

- Final chlorination led to increase in the formation of aldehydes in pre-ozonated water.

- Final chlorination led to remove ketones from pre-ozonated water.

- There was no correlation between TOC and total aldehyde and total ketone in all water samples.

\section{Acknowledgments}

Authors would like to thank the Hamadan Laboratory, Graduate School of Medical Sciences for help in analyzing the water samples. This article is extracted from the Master's thesis.

\section{Conflicts of Interest}

This study did not have any conflict of interest statement.

\section{References}

APHA, AWWA, WEF, (1998), Standard methods for the examination of water and wastewater Method 6252: disinfection by-products: aldehydes (20th ed.)American Public Health Association, American Water Works Association, Water environment Federation, Washington, DC (1998), pp. 651-659

Asgari G., Seid Mohammadi A., Mortazavi S.B. and Ramavandi B. (2013), Investigation on the pyrolysis of cow bone as a catalyst for ozone aqueous decomposition: kinetic approach, Journal of Analytical and Applied Pyrolysis, 99, 149-154.

Census of the Islamic Republic of Iran, 1385 (2006), "Islamic Republic of Iran". Archived from the original on 2011, 11-11. 
Cervi S. (1996), Formation and removal of aldehydes as ozonation by-products in a pilot-scale water treatment plant. University of Windsor, 2146.

Chiang P.C., Chang E.E., Chang P.C. and Huang C.P. (2009), Effects of pre-ozonation on the removal of THM precursors by coagulation, Science of the Total Environment, 407, 5735-42.

Chou C.Y., Huang C.P., Shang N.C. and Yu Y.H. (2009), Treatment of local scrubber wastewater for semiconductor by using photo-catalytic ozonation, Water Science and Technology, 59, 2281-2286.

Dabrowska A., Swietlik J. and Nawrocki J. (2003), Formation of aldehydes upon Cloz disinfection, Water Research, 37, 1161-1169.

Dabrowska A., Kasprzyk Hordern B. and Nawrocki J. (2005), Aldehydes Formation during Water Disinfection by Ozonation and Chlorination Process, Global NEST Journal, 7(1), 61-71.

Dabrowska A., Nawrocki J. and Szelag Wasielewska E. (2014), Appearance of aldehydes in the surface layer of lake waters, Environmental Monitoring and Assessment, 186, 4569-4580.

US Environmental Protection Agency, Method 556: Determination of carbonyl compounds in drinking water by pentafluorobenzylhidroxylamine derivatization and capillary gas chromatography with electron capture detection. Environmental Monitoring and System Laboratory, Cincinatti, OH. 1998.

Derrouiche S., Bourdin D., Roche P., Houssais B., Machinal C., Coste M., Restivo J., Órfão J.J.M., Pereira M.F.R., Marco $Y$ and Garcia-Bordeje E. (2013), Process design for wastewater treatment: catalytic ozonation of organic pollutants, Water Science and Technology, 68(6), 1377-1383.

EPA (1998), Method 556: determination of carbonyl compounds in drinking water by pentafluorobenzyl hydroxylamine derivatization and capillary gas chromatography with electron capture detection (Revision 1).

Faria P.C.C., Órfão J.J.M. and Pereira M.F.R (2006), Ozone decomposition in water analyzed by activated carbon: influence of chemical and textural properties, Industrial \& Engineering Chemistry Research, 45, 2715-2721.

Hammes F., Salhi E., Koster O. and Kaiser H.P. (2006), Mechanistic and kinetic evaluation of organic disinfection byproduct and assailable organic carbon (AOC) formation during the ozonation of drinking water, Water Research, 40, $2275-2286$.

Ivancev-Tumbas I. and Dalmacija B. (2001), Effects of coagulation processes on aldehydes formation in groundwater treated with common oxidative agents, Water Research, 35(16), 3950-3958.

Jung Y.J., Oh B.S., Kang J.W., Page M.A., Phillips M.J. and Mariñas B.J. (2007), Control of disinfection and halogenated disinfection byproducts by the electrochemical process, Water Science and Technology, 55(12), 213-219.

Karnik B.S., Davies S.H., Baumann M.J. and Masten S.J. (2005), The effects of combined ozonation and filtration on disinfection by-product formation, Water Research, 39, 2839-2850.

Kasprzyk-Horden B., Ziolek M. and Nawrocki J. (2003), Catalytic ozonation and methods of enhancing molecular ozone reactions in water treatment, Applied Catalysis B: Environmental, 46, 639-69.

Kiss Z.L., Szép A., Kertész S., Hodúr C and László Z. (2013), Treatment of waste thermal waters by ozonation and nanofiltraton. Water Sci Technol, 67(6), 1272-1279.

Müller A., Weiss S.C., Beißwenger J., Leukhardt H.G., Schulz W., Seitz W., Wolfgang K.L.R. and Weber W.H. (2012), Identification of ozonation by-products of 4-and 5-methyl-1H-benzotriazole during the treatment of surface water to drinking water, Water research, 46(3), 679-690.

Nawrochi J., Swietlik J., Raczyk-Stanislawiak U., Dabrowska A., Bilozor S. and Ilecki W. (2003), Influence of ozonation conditionson aldehyde and carboxylic acid formation, Ozone Science and Engineering, 25(1), 53-62.

Oliviero L., Barbier J. and Duprez D. (2003), Wet air oxidation of nitrogencontaining organic compounds and ammonia in aqueous media, Applied Catalysis B: Environmental, 40, 163-184.

Reungoat J., Macova M., Escher B.I., Carswell S., Mueller J.F and Keller J. (2010), Removal of micropollutants and reduction of biological activity in a full scale reclamation plant using ozonation and activated carbon filtration, Water Research, 44, 625-637.

Rivera-Utrilla J. and Sánchez-Polo M. (2002), Ozonation of 1, 3, 6-naphthalenetrisulphonic acid catalysed by activated carbon in aqueous phase, Applied Catalysis B: Environmental, 39, 319-329.

Schechter D.S. and Singer P.C. (1995), Formation of aldehydes during ozonation, Ozone Science and Engineering, 17, 53-59. 
Siddiqui M., Zhai W., Amy G. and Mysore C. (1996), Bromate ion removal by activated carbon, Water Research, 30(7), 1651-1660.

Sung M., Lee S.Z. and Chan H.L. (2012), Kinetic modeling of ring byproducts during ozonation of pentachlorophenol in water, Separation and Purification Technology, 84, 125-131.

Trussell R.R. and Umphres M.D. (1978), The formation of Trihalomethanes, American Water Works Association, 70(11), 604-612.

Weinberg H.S, Glaze W.H., Krasner S.W. and Sclimenti M.J. (1993), Formation and removal of aldehydes in plants that use ozonation, American Water Works Association, 85(5), 72-85.

Yang X., Jinfeng P., Chen B., Guo W., Liang Y., Liu W. and Liu L. (2012), Effects of ozone and ozone/peroxide pretreatments on disinfection byproduct formation during subsequent chlorination and chloramination, Journal of Hazardous Material, 239- 240, 348- 354. 